\title{
RANCANG BANGUN SISTEM AKUISISI DATA TEMPERATUR BERBASIS PC DENGAN SENSOR THERMOPILE MODULE (METODE NON-CONTACT)
}

\author{
Wildian dan Irza Nelvi Kartika \\ Jurusan Fisika Universitas Andalas \\ wildian_unand@yahoo.com
}

\begin{abstract}
ABSTRAK
Telah dilakukan penelitian rancang-bangun sistem akuisisi data temperatur berbasis PC dengan metode non-contact menggunakan sensor thermopile module TPMF1-G12-J4S\#2099. Sensor yang tersusun dari beberapa termokopel ini bekerja berdasarkan radiasi inframerah yang diterimanya dari obyek. Radiasi inframerah yang dipancarkan obyek tersebut sebanding dengan pangkat empat temperaturnya. Sinyal keluaran sensor (dengan fungsi transfer $V_{\text {out }}=0,009 T+1,3492$ dan koefisien korelasi $R^{2}=0,9963$ ) dikuatkan dengan menggunakan penguat non-inverting (dengan penguatan 2 kali). Sinyal itu kemudian dikonversi ke bentuk digital menggunakan ADC0804 dan dikirim ke PC melalui teknik antarmuka menggunakan port paralel (melalui konektor DB-25) yang ditampilkan di monitor PC menggunakan bahasa pemrograman Delphi 5. Dari hasil pengujian diperoleh kesalahan relatif maksimum sistem akuisisi data temperatur ini sebesar $0,048 \%$ dengan resolusi sebesar $0,31^{\circ} \mathrm{C}$.
\end{abstract}

Kata-kunci: temperatur, akuisisi data, thermopile TPMF1-G12-J4S\#2099, PC.

\section{PENDAHULUAN}

Temperatur merupakan salah satu aspek penting dalam kehidupan manusia sehingga banyak penelitian yang terkait temperatur (baik tentang sistem pengukuran maupun sistem pengontrolannya) dilakukan untuk diterapkan di berbagai bidang, seperti industri, kesehatan, dan peralatan rumah tangga.

Temperatur merupakan ukuran panas atau dinginnya suatu benda. Sifat fisis suatu zat atau benda dapat berubah apabila temperatur zat atau benda tersebut berubah. Oleh sebab itu, diperlukan alat yang dapat digunakan untuk mengukur temperatur. Saat ini telah banyak dikembangkan alat ukur temperatur digital yang memberikan kemudahan dalam pembacaan hasil ukur tanpa direpotkan dengan melihat secara teliti garis-garis skala sebagaimana pengukuran temperatur dengan termometer analog.

Pengukuran temperatur suatu obyek biasanya dilakukan secara kontak langsung dengan obyek yang diukur. Persoalannya muncul ketika alat ukur yang digunakan tidak memungkinkan untuk disentuhkan langsung dengan obyek yang diukur itu (seperti zat kimia yang sangat reaktif, atau obyek yang temperaturnya sangat tinggi, misalnya) karena dapat merusak alat ukurnya.

Pada dasarnya setiap benda memancarkan (emits) radiasi inframerah. Besar-kecilnya radiasi ini bergantung pada temperatur benda tersebut (Krane, 1992). Mata manusia tidak peka terhadap inframerah. Oleh sebab itu dibutuhkan alat bantu yang mampu mengukur temperatur benda melalui radiasi inframerah yang dipancarkan oleh benda tersebut. Alat bantu ini adalah sensor inframerah. Salah satu sensor temperatur yang mampu mendeteksi inframerah adalah thermopile. Sensor ini dapat mendeteksi temperatur $0^{\circ} \mathrm{C}$ maupun temperatur tinggi pada daerah-daerah yang sulit dijangkau oleh termometer biasa. 
Thermopile tersusun dari beberapa termokopel. Termokopel terbuat dari dua kawat logam yang berbeda dan disambung bersama-sama pada ujung yang satu (ujung pengindera atau ujung panas) dan berakhir pada ujung lain (titik acuan atau ujung dingin) yang dipertahankan pada suatu temperatur konstan yang diketahui (temperatur acuan). Ketika ujung sambungan termokopel dipanasi atau menerima panas, tegangan termionik kecil yang terjadi sebanding dengan temperatur yang muncul antara kawat sehingga dihasilkan tegangan keluaran sebagai fungsi dari temperatur tersebut. Efek termolistrik yang diakibatkan oleh potensial-potensial kontak pada titik-titik sambung ini dikenal sebagai efek Seebeck (Fraden, 1996). Besarnya ggl termal tergantung pada bahan kawat yang digunakan dan pada selisih temperatur antara titik-titik sambung, yaitu

$$
V \equiv \alpha\left(T_{1}-T_{2}\right)
$$

dimana :

$$
\begin{aligned}
& V=\text { tegangan Seebeck }(\mathrm{V}) \\
& \alpha=\text { koefisien Seebeck }\left(\mathrm{V} /{ }^{\circ} \mathrm{C}\right) \\
& T_{1}-T_{2}=\text { selisih temperatur antara sambungan }\left({ }^{\circ} \mathrm{C}\right)
\end{aligned}
$$

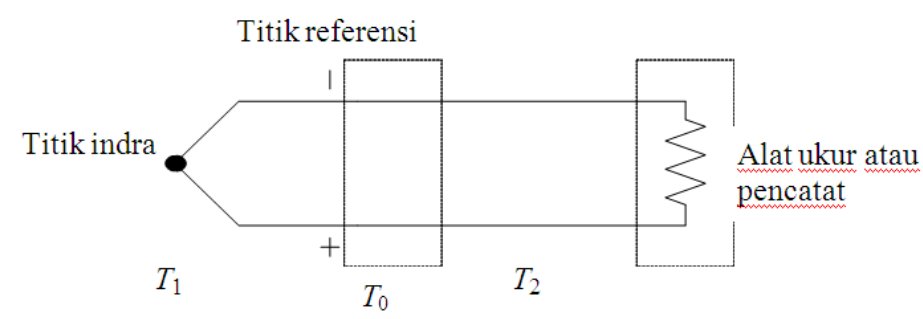

Gambar 1: Rangkaian dasar termokopel (Cooper, 1999)

Seiring perkembangan teknologi semikonduktor modern, saat ini telah dipasarkan sensor thermopile dalam keping silikon kecil. Struktur utama dari thermopile ini terdiri dari membran, absorber (penyerap) dan beratus-ratus termokopel yang disusun secara seri.

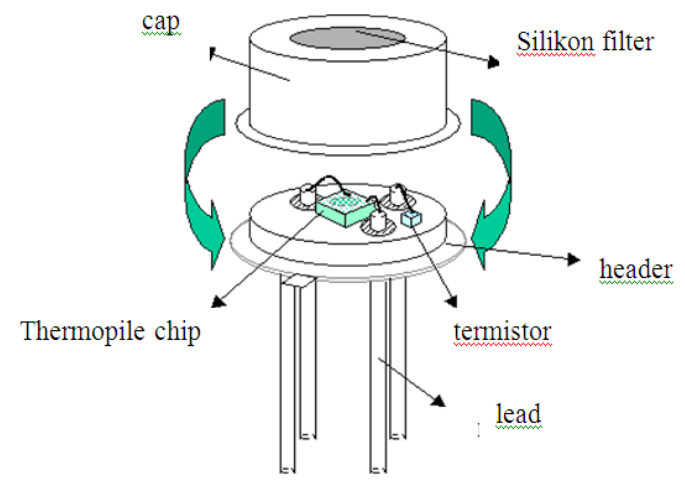

Gambar 2: Struktur Thermopile dengan selubung (www.Perkinelmer.com)

Membran terbuat dari lapisan tipis yang sensitif terhadap temperatur panas. Di tengah membran, terdapat material absorber yang akan menimbulkan panas ketika menerima radiasi inframerah. Perbedaan temperatur antara persambungan panas dan persambungan dingin akan menghasilkan tegangan yang merupakan keluaran dari sensor. Sensor ini sangat cepat merespon dan mudah dalam pengoperasiannya.

Penelitian tentang alat ukur temperatur ini sebelumnya telah dilakukan Rhedatul (2004) dengan menggunakan thermopile module tipe TPMF1-G12-J4S\#2099 sebagai sensor, 
mikrokontroler AT89C51 sebagai pengontrol dan seven segment sebagai penampil hasil ukur. Namun, dengan basis sistem dan tampilan yang demikian tidak memungkin pengguna (user) untuk mengamati perubahan temperatur dalam bentuk grafik ataupun menyimpan data hasil pengukuran.

Penelitian yang penulis sajikan dalam makalah ini juga menggunakan sensor thermopile module tipe TPMF1-G12-J4S\#2099, namun dengan basis komputer pribadi (personal computer, PC) di mana sistem akuisisi data dan tampilannya pada monitor dirancang dengan menggunakan Delphi 5.

\section{BAHAN DAN METODE}

Rancang-bangun sistem akuisisi data temperatur ini terdiri atas dua bagian: rancangbangun perangkat keras (hardware) dan rancang-bangun perangkat lunak (software). Diagram blok sistem ditunjukkan pada Gambar 3.

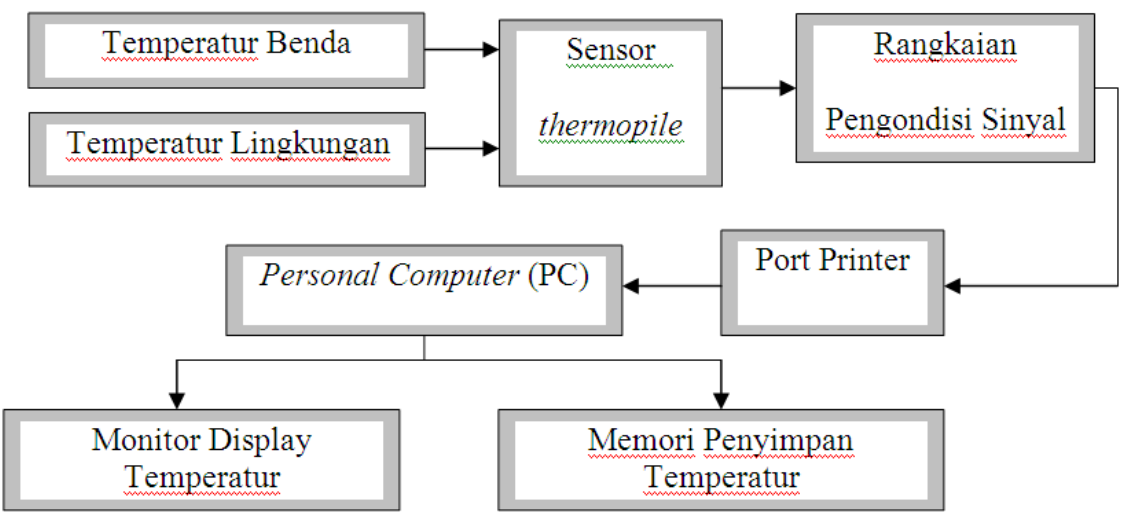

Gambar 3: Diagram blok sistem pengukuran temperatur non-kontak berbasis PC.

Sensor thermopile berfungsi mengonversi perubahan besaran fisis (temperatur obyek) menjadi perubahan tegangan dengan memanfaatkan radiasi inframerah yang dipancarkan oleh obyek. Di dalam module, thermopile telah terintegrasi dengan termistor yang berfungsi untuk mengukur temperatur lingkungan. Sensor ini membutuhkan catu daya $+5 \mathrm{~V}$ sebagai sumber tegangannya. Skematik sensor thermopile module diperlihatkan pada Gambar 4.

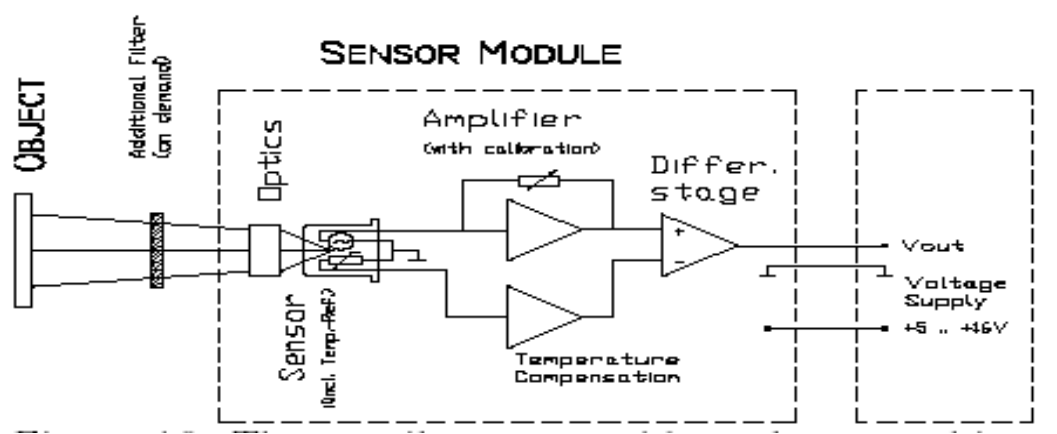

Gambar 4: Skematik sensor thermopile module (www. perkinelmer.com)

Sinyal keluaran sensor dikuatkan oleh penguat non-inverting lalu dikonversi menjadi sinyal digital dengan menggunakan $A D C 0804$. Selanjutnya sinyal ini dihubungkan ke PC (Personal Computer) melalui port paralel LPT1 (Fahrizal, 2005).

Pada penelitian ini, penulis menggunakan port paralel dengan konektor female DB-25 sebagai port fisiknya. Pada dasarnya, port ini memiliki total keluaran digital sebanyak 12 pin dan total masukan digital sebanyak 5 pin, yang digolongkan menjadi 3 bagian 
(Gambar 3), yaitu : Saluran Data (pin 2 sampai 9), Saluran Status (pin 10, 11, 12, 13, dan 15), dan Saluran Kendali (pin 1, 14, 16, dan 17).

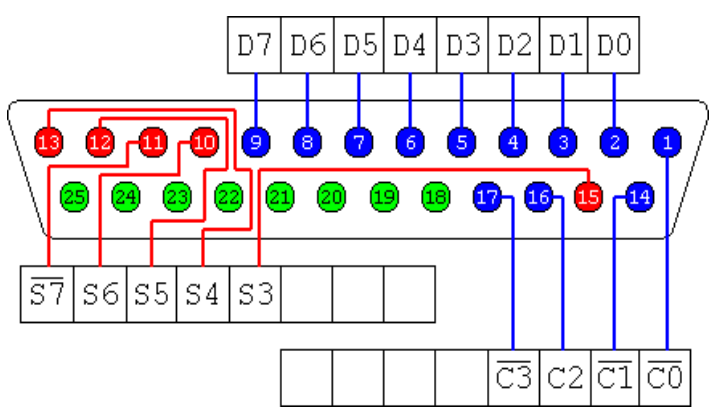

Gambar 5: Konektor DB-25 (www. Demarda.com)

Skematik rangkaian lengkap system akuisisi data temperature berbasis PC dengan sensor thermopile module ini diperlihatkan seperti pada Gambar 6.

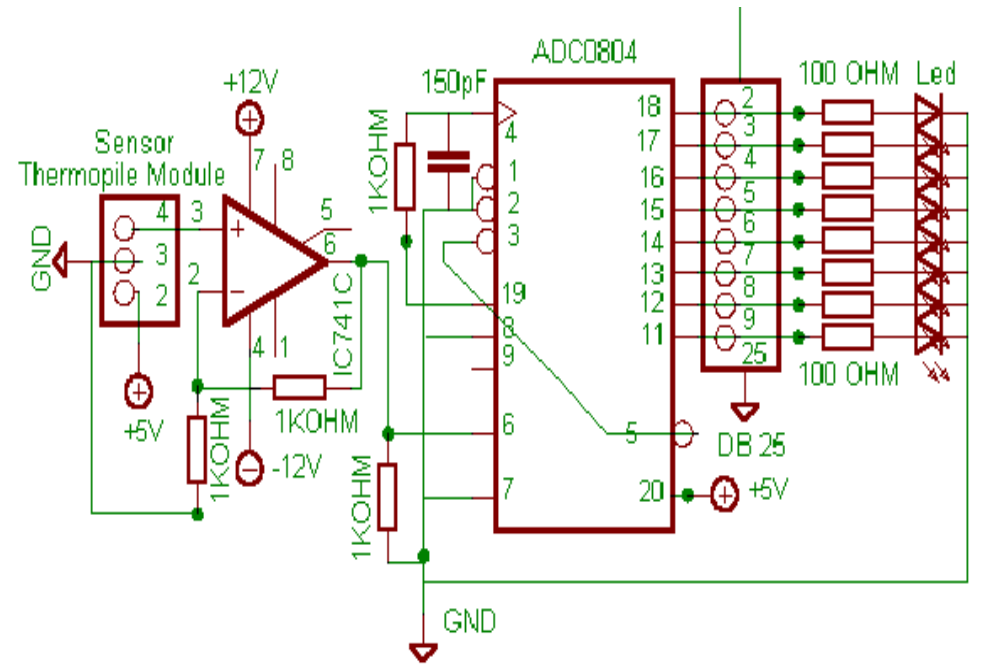

Gambar 6: Skematik rangkaian sistem akuisisi data temperatur berbasis PC.

Untuk menampilkan hasil ukur temperatur dalam bentuk angka dan grafis digunakan program Delphi 5, dengan diagram alir (flowchart) seperti pada Gambar 7. 


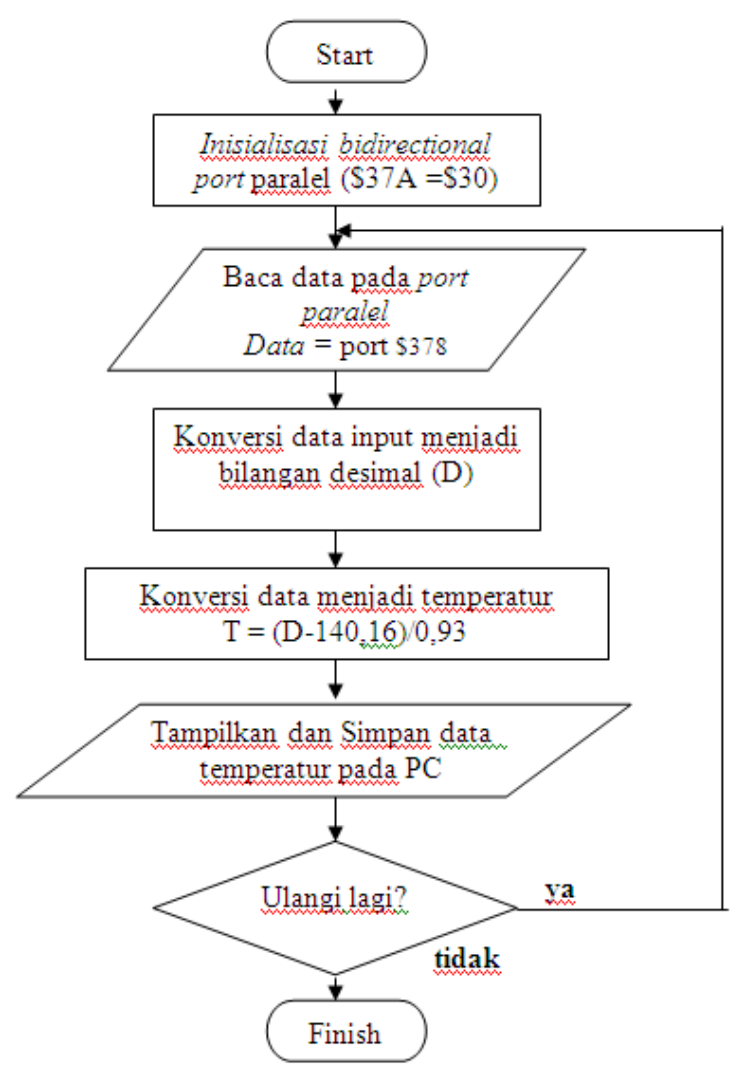

Gambar 7: Diagram alir program sistem akuisisi data temperatur pada PC.

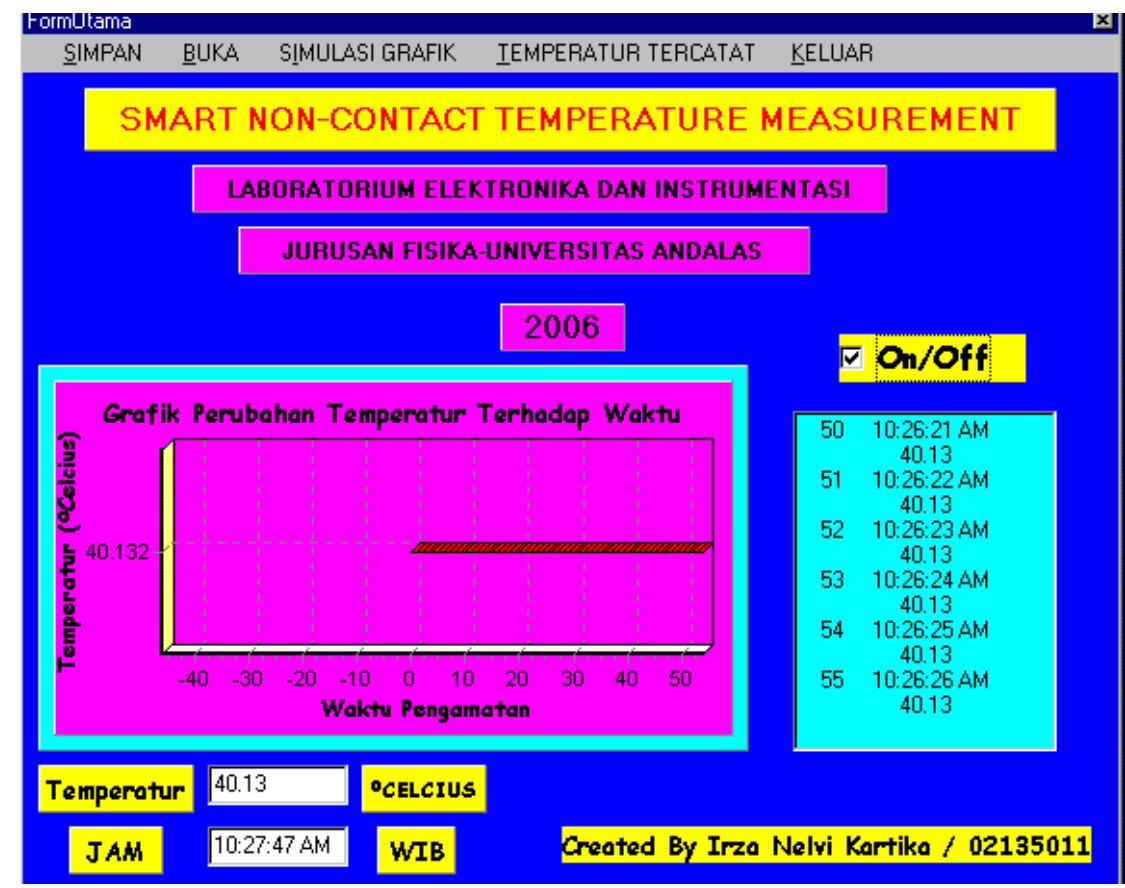

Gambar 8: Bentuk tampilan sistem akuisisi temperatur pada monitor PC. 


\section{HASIL DAN DISKUSI}

Dengan menggunakan program Delphi 5, diperoleh hasil bentuk tampilan sistem akuisisi temperatur pada monitor PC seperti pada Gambar 8. Pada gambar tersebut tampak bahwa untuk akusisi data dengan temperatur yang konstan (dalam hal ini pada temperatur $40,13^{\circ} \mathrm{C}$ ) memperlihatkan kurva berupa garis datar. Pada monitor juga terlihat waktu ketika data temperatur itu diakuisisi, yaitu pada pukul 10:27:47 WIB.

Kurva karakteristik tegangan keluaran sensor thermopile module terhadap temperatur diperlihatkan pada Gambar 9. Berdasarkan grafik tampak bahwa tegangan keluaran sensor sebanding dengan temperatur obyek, dengan fungsi transfer seperti ditunjukkan Persamaan (2).

$$
V_{\text {out }}=0,009 T+1,3492
$$

dengan $V_{\text {out }}=$ tegangan keluaran sensor (volt), $T=$ temperatur obyek $\left({ }^{0} \mathrm{C}\right)$

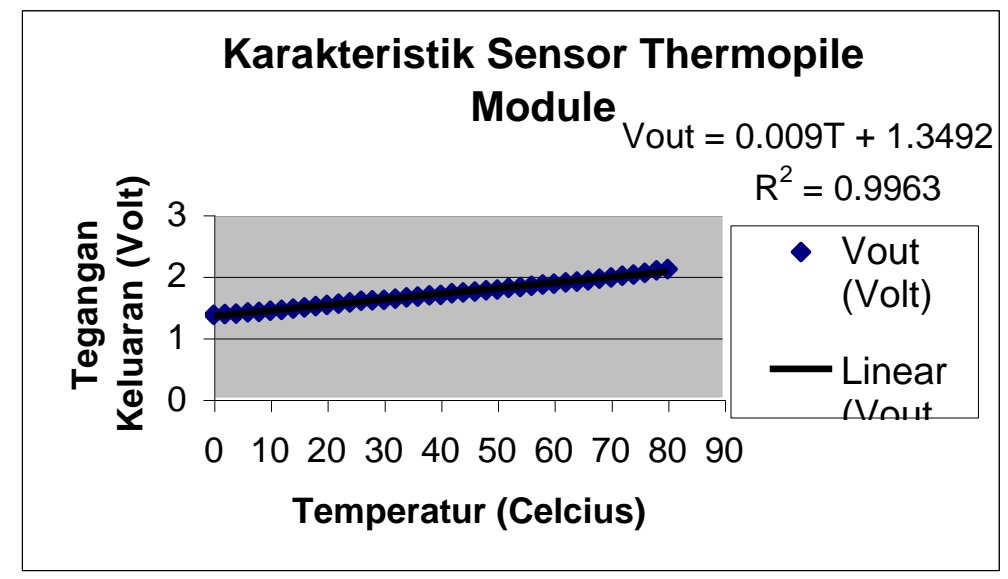

Gambar 9: Karakteristik sensor thermopile module

Dari Persamaan (2) diperoleh sensitivitas sensor sebesar $0,009 \mathrm{~V} /{ }^{\circ} \mathrm{C}$, dengan offset sebesar 1,349 V. Gambar 4 juga memperlihatkan derajat korelasi linier yang cukup baik $\left(R^{2}=0,9963\right)$ dari grafik tersebut.

Untuk mengetahui tingkat ketepatan pengukuran, maka dilakukan pengukuran temperatur sebanyak 10 kali pada temperatur $26,9{ }^{\circ} \mathrm{C}$ (dengan alat-ukur pembanding: termometer digital Philip Harris). Hasilnya diperlihatkan pada Tabel 1.

Tabel 1: Hasil pengukuran temperatur dengan sistem akuisisi data berbasis PC.

\begin{tabular}{|c|c|c|}
\hline No & Sensor Thermopile Module $\left({ }^{0} \mathrm{C}\right)$ & Philip Harris $\left({ }^{\circ} \mathrm{C}\right)$ \\
\hline 1 & 26,71 & 26,9 \\
\hline 2 & 26,71 & 26,9 \\
\hline 3 & 27,78 & 26,9 \\
\hline 4 & 27,78 & 26,9 \\
\hline 5 & 26,71 & 26,9 \\
\hline 6 & 26,71 & 26,9 \\
\hline 7 & 26,71 & 26,9 \\
\hline 8 & 25,63 & 26,9 \\
\hline 9 & 26,71 & 26,9 \\
\hline 10 & 26,71 & 26,9 \\
\hline
\end{tabular}


Berdasarkan Tabel 1 diperoleh temperatur rata-rata hasil pengukuran sebesar $26,816{ }^{\circ} \mathrm{C}$ dan simpangan maksimum sebesar $0,084^{\circ} \mathrm{C}$ terhadap hasil pengukuran menggunakan termometer pembanding. Itu berarti, hasil pengukuran temperatur dengan sistem akuisisi data ini dapat dipercaya keakuratannya.

Resolusi sistem pengukuran temperatur berbasis PC ini dapat dihitung dengan menggunakan Persamaan (3).

$$
\text { Resolusi alat-ukur }=\frac{T_{m a k s P C-} T_{\min . P C}}{256}
$$

dengan:

$$
\begin{aligned}
& T_{\text {maks.PC }}=\text { temperatur maksimum yang dapat ditampilkan PC }\left({ }^{\circ} \mathrm{C}\right) \\
& T_{\text {min.PC }}=\text { temperatur maksimum yang dapat ditampilkan PC }\left({ }^{\circ} \mathrm{C}\right) \\
& 256 \text { = data desimal maksimal (dari 0-255) yang masuk ke PC. }
\end{aligned}
$$

Berdasarkan data hasil pengukuran, maka diperolehlah resolusi alat ukur itu sebesar $0,31^{\circ} \mathrm{C}$. Untuk menghitung besar kesalahan relatif sistem pengukuran temperatur menggunakan sensor Thermopile Module digunakan Persamaan (4.13).

$$
\text { Kesalahan Relatif }(\%)=\frac{\Delta T}{T_{\text {maksimum }}-T_{\text {min imum }}} \times 100 \%
$$

dengan:

$$
\begin{aligned}
& \Delta T=\text { selisih temperatur acuan dengan temperatur sensor Thermopile Module }\left({ }^{0} \mathrm{C}\right) \\
& T_{\text {maksimum }}=\text { temperatur acuan maksimum }\left({ }^{\circ} \mathrm{C}\right) \\
& T_{\text {minimum }}=\text { temperatur acuan minimum }\left({ }^{\circ} \mathrm{C}\right)
\end{aligned}
$$

Kesalahan relatif maksimum sistem pengukuran temperatur menggunakan sensor thermopile module ini adalah $0,048 \%$.

\section{KESIMPULAN}

Berdasarkan pengujian dan analisis data hasil pengukuran yang telah dilakukan terhadap sistem akuisisi data berbasis PC dengan sensor thermopile module ini maka dapat diambil kesimpulan sebagai berikut:

1. Sistem akuisisi data tersebut dapat digunakan untuk mengakuisisi data temperatur suatu obyek yang memancarkan radiasi inframerah.

2. Perubahan tegangan keluaran pada sensor thermopile module sebanding dengan perubahan temperatur, dengan fungsi transfer: $V_{\text {out }}=0,009 T+1,3492$, yang menunjukkan sensitivitas alat sebesar 0,009 volt/0C, dan nilai offset keluarannya sebesar $1,349 \mathrm{~V}$.

3. Linieritas sistem ini cukup baik,

4. data berbasis PC ini adalah $0,048 \%$ dan resolusinya sebesar $0,310 \mathrm{C}$. dengan derajat korelasi R2=0,9963.

5. Kesalahan relatif maksimum sistem akuisisi

\section{SARAN}


Berdasarkan hasil penelitian yang telah dilakukan, penulis menyarankan bagi peneliti lain yang berminat melakukan penelitian tentang pengukuran temperatur non-kontak ini untuk:

1. Membuat sistem akuisisi data berbasis laptop dengan antarmuka melalui port USB karena port paralel sudah semakin jarang digunakan.

2. Mengembangkan pengukuran temperatur non-kontak dengan memanfaatkan sistem telemetri (untuk pengukuran jarak jauh).

\section{DAFTAR PUSTAKA}

1. Cooper, WD., 1999, Instrumentasi Elektronik dan Teknik Pengukuran, Erlangga, Jakarta

2. Fahrizal, 2005, Rancang-Bangun Alat-Ukur Densitas Zat Cair Berbasis PC Dengan Menggunakan Sensor Strain Gauge,Tugas Akhir, UNAND, Padang

3. Fraden, J., 1996, Handbook Of Modern Sensors Physics second edition, Themoscan Inc., San Diego, California

4. Rhedatul, H., 2002, Penentuan Karakteristik Dari Sistem Pengukuran TemperaturTanpa Sentuhan Dengan Sensor Thermopile Inframerah, Tugas Akhir, UNP, Padang

5. Krane, K., 1992, Fisika Modern, UI, Jakarta

6. Dedi, M., 2005, Antarmuka Saluran Paralel PC-IBM, 1 hlm, http://www.Dermarda's.com, 19 Desember 2005

7. Perkinelmer, 2003,TPMI ${ }^{\mathrm{TM}}$ - Thermopile Sensor Module With Integrated Signal Processing, http://www.Perkinelmer.Optoelektronics.com 